\title{
Küçük Asya Klasik Dönem Historiografların Persika Eserleri ve Perslere Bakış Açıları
}

\author{
The Historiographers's of Classical Asia Minor's Persica Works and Their \\ Perspectives on the Persians
}

\section{Sevgi SARIKAYA*}

Özet: Bu makale, Kü̧̈ük Asya yerel historiograflarının Pers İmparatorluğu üzerine yaptıkları çalışmaları ve Pers/Akhaimenid'lere yaklaşımlarını konu edinmektedir. Tarihyazıcıları genellikle eserlerini Pers Tarihi

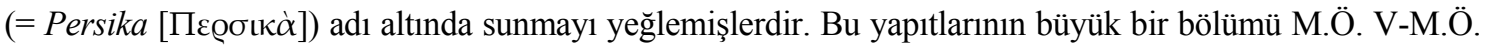
IV. yüzyılda yaşamış Küçük Asya yerel tarih yazarları tarafından kaleme alınmış fragmanlardan ibarettir. Tarihyazıcıların Perslere bakış açıları ve oryantasyonlarının neler olduğunu tespit etmek amacıyla günümüze kalan fragmanların odaklandıkları alan, metne yayılan imge, izlek ve temsil biçimleri incelenmiştir. Çalışma esasen Miletos'lu Dionysios, Lesbos'lu Hellanikos, Lampsakos'lu Kharon, Knidos'lu Ktesias, Kolophon'lu Dinon ve Kyme'li Herakleides'in yapıtlarının incelemesinde yoğunlaşsa da, söz konusu yazarların Pers yaklaşımına açıklık kazandırmak amacıyla Herodotos'un "Historiai" adlı eserine konu bağlamında özellikle değinilmiştir. Yazar çağının zihinsel izlenimini yansıtması, ardılları üzerinde etkin rol oynaması, metodolojisi ve nesnellik ilkesi, Hellenlerin üstünlük ideolojileri ve Perslere önyargılarının yansımalarının izlerinin gözlenebilmesi açısından yeğlenmiştir. Makale, imgelerde yaratılan yaygın Pers tasavvurunu serimleyip betimlemek adına konuyla bağıntılı dönemin antik yazarlarının yaygın ve öznel yargıları konu kapsamında ele alınıp derlendiği verilerin genel bir değerlendirmesiyle sonlandırılmıştır.

Anahtar Sözcükler: Persika, Miletos'lu Dionysios, Lesbos'lu Hellanikos, Lampsakos'lu Kharon, Herodotos, Knidos'lu Ktesias, Kolophon'lu Dinon ve Kyme'li Herakleides.

Abstract: This paper concerns the works of local Asia Minor historiographers' concerning the Persian Empire and their views of the Persians/Achaemenids. The works of these historiographers are called Persica. A large part of the Persica consists of fragments which were written by the local historians of Asia Minor during the $5^{\text {th }}$ and $4^{\text {th }}$ centuries B.C. The surviving fragments provide general information about the content, text and the copying of earlier references and the spread of this material, employed in order to determine their perspectives concerning the Persians and their orientations. This article mainly addresses the Persica works of Dionysius of Miletus, Hellanicus of Lesbos, Charon of Lampsacus, Ctesias of Cnidus, Dinon of Colophon and Heracleides of Cumae, in addition to the Histories of Herodotus, which have been examined within the framework of this subject. This study concludes with a general evaluation, compiling the data which treats exhaustively of these ancient writers' shared and subjective judgments.

Keywords: Persica, Dionysius of Miletus, Hellanicus of Lesbos, Charon of Lampsacus, Herodotus, Ctesias of Cnidus, Dinon of Colophon and Heracleides of Cumae.

\footnotetext{
* Arş. Gör., Akdeniz Üniversitesi, Edebiyat Fakültesi, Eskiçağ Dil. ve Kült. Böl., Antalya, sevgisarikaya@akdeniz.edu.tr
} 
M.Ö. yak. 546 yılından itibaren Pers İmparatorluğu'nun genişleyen egemenlik sahasıyla koşut giden ilerlemelerin Klasik Dönem kent devletlerinin dikkatini Akhaimenid'ler üzerine çekmesine neden olduğu görülür. Bu gelişme imgesel ve gerçek coğrafya eriminin küçülmesine; Küçük Asya ve Hellenlerin idari yetkesi altındaki Perslerle yakın ilişkiler içerisine girmeye zorunlu kıldı. Persleri tanıma ve egemenlik yetkilerinin erk/kudret sınırlarını bilme gerekliliği, Küçük Asya ve Hellen historiograflarını Perslerin siyasi-politik, sosyo-ekonomik, kültürel ve dinsel yapılarını incelemeye, irdelemeye sevk etmiş olsa gerektir. Ancak yazın tasavvurunun bir araştırma söyleminden ideolojik ve öznel fikirlerin dillendirildiği bir kuruma dönüşmekle başkalaşma/ayrıştırma zihniyetine hizmet ettiği anlaşılmaktadır. Bunun göstergesi yazarların tarihyazımlarının dokusunda Persler yerine ona tekabül eden "barbar" terimini tercih etmeleridir. Hellenlerin Homeros'tan itibaren kendilerinden olmayanları ve Hellence konuşmayanları belirtmek amacıyla kullandıkları barbar (= barbaroi [ $\beta \alpha \dot{\varrho} \beta \alpha \varrho o t])$ kavramı önceleri Hellenlerin kendilerini diğer uluslardan ayrı bir kimlik ve lisana sahip olduklarını belirtmek amacıyla kullanılmıştır. M.Ö. V. yüzyılın ortalarından itibaren farklı milletleri de kapsamasına rağmen, bu kavram giderek Perslerle özdeşleştirilip sınırlandırmaya başlanmıştır. Ancak süreç içerisinde Hellenler barbar kelimesini stereotip beklentilerine göre kullanıp içselleştirerek olumsuzlaştırılan bir vaziyetalış haline dönüştürmüşlerdir. Öyle ki, Makedonyalılar örneğinde olduğu üzere zamanla birbirlerini küçümsemek ve aşağısamak adına bu terimi kullanmışlardır (Dem. Phil. (3) IX. 31).

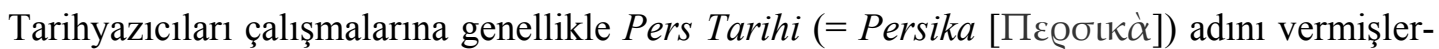
dir. Pers Tarihi'ne ilişkin Klasik Dönem'den M.Ö. II. yüzyıla kadar bilinen on altıya yakın eser kaleme alınmıştır. Bu yapıtların ortak akıbeti fragmanlar halinde ve antik yazarların özetleri, atıflarıyla günümüze kadar ulaşmasıdır. Miletos'lu Dionysios, Lesbos'lu Hellanikos, Lampsakos'lu Kharon, Knidos'lu Ktesias, Kolophon'lu Dinon ve Kyme'li Herakleides'in eserlerinin içeriği hakkında genel bilgi edinmek mümkünken; ne var ki, on bir kitaptan bir-iki satırı geçmeyecek kadar küçük parçalar ya da Persika adından başka geriye bir şey kalmamıştır. Kitaplarının neredeyse bütünü yitik olan historiograflar şunlardır: M.Ö. yak. 300 yılında yaşamış Kolophon'lu Hermesianaks (FGrHist III C 1691 T 1-2 F 1-2); muhtemelen M.Ö. V./IV. yüzyılda yaşamış Barsuma (FGrHist III C 1695 T 1); M.Ö. III. yüzyıl yazarlarından Diogenes (FGrHist III C 1692 F 1); Diokles (FGrHist III C 1693 F 1-2); Sinop'lu Baton (FGrHist III A 268 T 1=Strab. XII. 3. 11 c. 546); M.Ö. yak. II. yüzyıl historiograflarından Pieria'l1 Kriton (FGrHist III A 277 T 1=Suda $\kappa$ s.v. $373<$ Koít $\omega v=$ Kriton>); Samos'lu Agatharkhides (FGrHist III A 284 F 1=Plut. Parall. Min. 2 a); Miletos'lu Aristeides (FGrHist III A 286 F 20=Plut. Parall. Min. 4 a); Korinthos'lu Khrysermos (FGrHist III A 287 F 4=Plut. Parall. Min. 10 a); Ktesiphon (FGrHist III A 294 F 2=Plut. De fluv. XXIII. 1) ve Nisibis'li Pharnukhos (FGrHist III C 1694 T 1) dur.

Tarihi olayların sağlıklı yorumlanması açısından büyük bir kayıp olan fragmanlar yazarların objektifliklerini, güvenilirliklerini, tarihyazımı kriterlerini, kurgularını, kullandıkları kaynakları, dil ve üsluplarının kıyaslamalı analizini zorlaştırmaktadır. Bu konuda Halikarnassos'lu Dio-

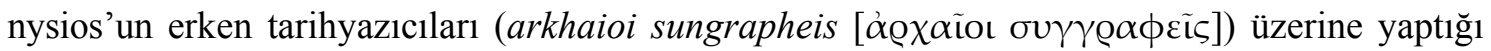
stil kritik analizlerine güvenmekten başka alternatif gözükmemektedir. Halikarnassos'lu Dionysios'a (Thuk. 5=FGrHist III B 323a T 1-8 'Hellanikos') göre, Herodotos haricinde Samos'lu Eugeon; Prokonnesos'lu Deiokhos; Paros'lu Eudemos; Phygela'lı Demokles; Miletos'lu Hekataios; Argos'lu Akusilaos; Lampsakos'lu Kharon; Khalkedon'lu Melesagoras gibi Thukydides'in öncülleri benzer konular seçer ve aynı anlatım becerileri sergilerlerdi. Peloponnesos Savaşı'ndan kısa süre önce dünyaya gelip Thukydides'in zamanına kadar yaşayanlar arasında ise, Lesbos'lu Hellanikos; Sigeion'lu Damastes; Khios'lu Ksenomedes; Lydia'l1 Ksanthos ve daha birçokları vard. Dionysios'un (Thuk. 5=FGrHist III B 323a T 1-8 'Hellanikos') 
anlatısina istinaden bu historiograflardan Eudemos, Damastes gibi bazlları Hellen (= Hellenika ['E $\lambda \lambda \eta v \iota \kappa \alpha ́]$ ); Kharon, Hellanikos gibi bazıları da farklı halklar yani barbar tarihi (= barbarika [ $\beta \alpha \varrho \beta \alpha \varrho \iota \kappa \alpha ́])$ üzerinde yoğunlaşır, onları birbirleriyle bağıntılayıp sentezlemezlerdi. Aksine her bir ulus ve kenti ayrı bir çerçevede ele alıp değerlendirirlerdi. Tek ve aynı nesne karşısında her bir halk ve kentlerin yerli ahalisinin muhafaza ettikleri, ortak kanının kayda geçirildiği,

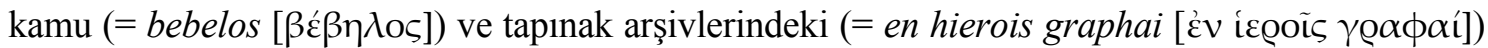
belgeleri kullanırlardı. Yazara göre, dokümanları herhangi bir ekleme ya da çıkarma yapmadan olduğu gibi aktarırlardı. Bu söylence yüklü bazı tiyatral değişkenler günümüz insanına saçma gelecek nitelikteydiler (ayrıca bk. Strab. VII. 3. 6 c. 299). Erken dönem tarihyazıcıların hepsinin üzerinde uğraş verdikleri neredeyse birbirinin aynısı olan üslupları; berrak, yalın, sade, veciz, konuya uygun düşen ve usta bir yeteneğin kapsamlı anlatım özelliklerinden hiçbirini sergilemezlerdi (konuya ilişkin detaylı bilgi için bk. Toye, 1995, 279-302; Fowler, 1996, 62-87).

Klasik Dönem historiograflardan Pers tarihine ilişkin ilk çalışmayı M.Ö. yak. 460-430 yıllarında yaşamış Miletos'lu Dionysios'un Ion diyaleğinde kaleme aldığı Persika adlı yapıtı

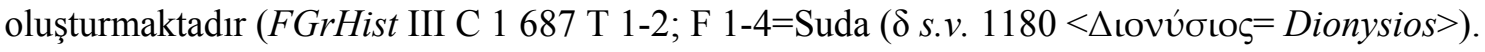

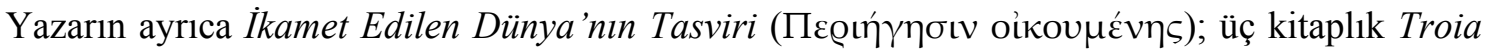
Savaşl; Mythika; yedi kitaplık Kyklon Historikon çalışmaları da bilinmektedir (FGrHist III C 1

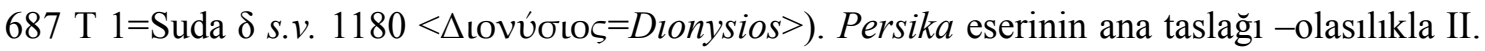
Kyros'la başlamakta- II. Kambyses'in hükümdarlığının sonundan I. Dareios'un krallığının sonuna kadarki süreci kapsamaktadır. Aynı zamanda "Dareios'tan Sonraki Olaylar" (= ta meta

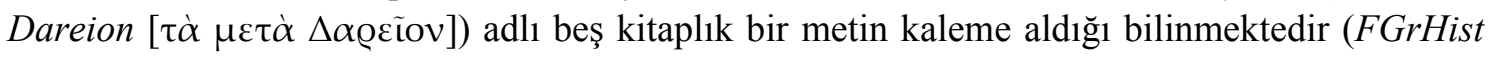
III C 1687 F 1-4=Schol. Dion. Thrak. III. 183; Schol. Hdt. III. 61; Schol. Hom. Il. II. 159). Bu çalışma Kserkses'in hükümdarlığında yoğunlaşmış ve dönem itibariyle M.Ö. 480-479 y1llında vuku bulan Pers Savaşları'nı konu edinmektedir (Drews, 1973, 36; Lenfant, 2007, 201; Llewellyn, \& Robson, 2010, 48). Yazarın eseri kaleme almasındaki amaç muhtemelen Lampsakos'lu Kharon gibi Hellenlerin Kserkses'in ordusuna karşı kazandıkları zaferin anısını yaşatmak olsa gerektir.

Persika adlı bir diğer çalışmayı ise, Miletos'lu Dionysios'la aynı jenerasyondan Lesbos'lu Hellanikos'un (M.Ö. yak. 480-407/406) yapıtı oluşturmaktadır (FGrHist I A 4 F 59-63; III C 1 687a T 1-3; F 1-4). Hellanikos'un çok yönlü bir tarihyazımı benimsediği görülmekte ve çeşitli konuları kapsayan birçok esere imza attığı anlaşılmaktadır. Kendi bilimsel ve ahlaki teoremlerini yansıttığı Phoronis, Deukalionia, Atlantis, Asopis ve Troika olmak üzere beş mitoloji kitabı bulunur (FGrHist I A 4 F 1-5; 6-18; 19-21; 22; 23-31). Yazarın adından siklıkla söz ettiren başlıca yapıtları etnografik çalışmalarıdır. Eserleri esas itibariyle Aiolika; Lesbiaka; Argolika; Peri Arkadias; Boiotika; Thessalika gibi (FGrHist I A 4 F 32; 33-35; 36; 37; 50-51; 52) Hellence konuşan halklar üzerine yoğunlaşsa da antikçağda Hellen asıllı olmayanları belirtmek amacıyla barbar şeklinde nitelendirdikleri, aralarında Perslerin de bulunduğu Aigyptiaka; Kypriaka; Lydiaka; Persika; Skythika gibi (FGrHist I A 4 F 53; 57; 58; 59-63; 6465) çeşitli halkları da kapsamaktadır. Bu etnografik çalışmaların geneli insan karakterlerinin analizini, gelenek-görenekleri, tarihsel olayları, eserlerinde standart bir form olan mitolojik şecereleri çerçevesinde betimlemektedir. Persika adlı yapıtından yalnızca on bir fragman

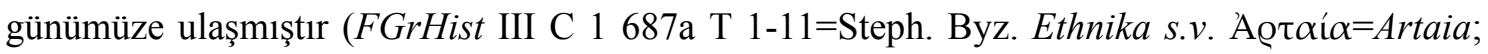
$\mathrm{X} \alpha \lambda \delta \alpha \tilde{i} \mathrm{o}=$ Khaldaioi; Schol. Aristoph. Av. str. 1021). Bu parçaların içeriğinden anlaşıldığ kadarıyla Hellen yazarları arasında Assur ve Babil dönemlerinden başlayıp Medlerden Perslere kadar uzanan geniş kapsamlı tarihyazımına öncülük etmiş gözükmektedir (FGrHist I A 4 F 177; III C 1 687a F 2). Hellanikos Persika kitabında Akhaimenid Krallı̆̆ı'nın tarihi olaylarına (FGrHist I A 4 F 179): Kambyses'in öldürülmesine (FGrHist I A 4 F 177); Dareios'un 
hükümdarlığına (FGrHist I A 4 F 182-183); Kserkses'in Hellas seferine yer vermiştir. Bunun yanı sıra eserinde Perslerin örf ve adetlerine de değinmiştir (FGrHist I A 4 F 184; ayrıca bk. Llewellyn, \& Robson 2010, 49 dn. 128). Ancak bazı Perslerin ölülerini yaktığı gibi Akhaimenid törelerine ilişkin anlatısında, Knidos'lu Ktesias'ın okuyucusuna yalan bilgiler sunduğuna dair eleştirilerine maruz kalmaktan kurtulamamıştır (FGrHist III C 1688 F 16 (62)=Bib. 72. 43b344a19 'Ktesias').

Perslere yoğun ilgi duyan bir diğer tarihyazıcısı ise, M.Ö. V. yüzyılda yaşamış Lampsakos'lu Kharon'dur (FGrHist III A 262 F 3; III C 1 687b T 1; F 1-6). Historiografın bu yapıt haricinde Aithiopika; dört kitaplık Hellenika; iki kitaplık Peri Lampsakou; Lybika; Lakedaimonia prytanis ve arkhon'larl; Khronika; Horoi Lampsakenon; iki kitaplık Ktiseis; Minos yasalarını anlatan üç kitaplık Kretika ile Herakles Sütunları civarına yapılan seferleri konu edindiği Periplous adlı eserleri kaleme aldığı bilinmektedir (FGrHist III C 1 687b T 1=Suda $\chi$ s.v. $136<$ Xó $\varrho \omega v=K h a-$ ron>). Ne yazık ki, iki kitaplık olduğu ileri sürülen Persika adlı çalışmasından günümüze alıntılar dışında hiçbir fragman ulaşmamıştır. Kalan parçalardan Persika kitabının örüntüleri (incelemenin odaklandığ1 alan) genel olarak çıkarılabilmektedir. Kharon (FGrHist III A 262 F 14; III C 1 687b F 1=Tert. An. 46)'da Med kralı Astyages'in rüyasında kızı Mandane'nin Kyros'a hamile kaldığına ilişkin değinisinden anlaşıldığı üzere Herodotos gibi eserini Büyük II. Kyros'un doğumu ve tahta geçişiyle başlatır. Onun Med ve Lydia krallıklarını devirip hakimiyetine alışıyla devam eder (FGrHist III A 262 F 9; III C 1 687b F 4=Plut. mor. XI. 859 ab: De Herod. 20: 'Paktyas isyanı ardından Khios'a sığınması'). Olasılıkla çalışma Kambyses'ten Dareios'a kadar cereyan eden olayları da kapsar. Ionia Ayaklanması ile Sardeis kuşatması (FGrHist III A 262 F 10; III C 1 687b F 5=Plut. mor. XI. 861 a-d: De Herod. 24); ayrica Gobryas oğlu Mardonios komutasındaki Pers donanmasının Athos Dağı dolaylarında firtınaya yakalanmasıyla (FGrHist III A 262 F $3 a-b$; III C 1 687b F 1=Ath. Deip. IX. 51; Ael. Var. I. 15) ilintili fragmanlardan eserin esasen I. Dareios ve Kserkses' in Küçük Asya'daki icraatlarında yoğunlaştığ1 düşünülebilir. Sürgündeki Themistokles'in Kserkses'in ölümünün ardından oğlu Artakserkses'e sığındığ ibarelerinden I. Artakserkses'in hükümdarlığına da yer verdiği sonucu çıkar (FGrHist III A 262 F 11; III C 1 687b F 6=Plut. Them. XXVII. 1). Ancak olay örgülerinin detaylara ne kadar girdiği, çalışmasını hangi zaman aralığıyla sınırladığını belirlemek şu an itibariyle mümkün değildir.

Pers ve döneme ilişkin güvenilir, başka yerden edinilmesi mümkün olmayan eşsiz bilgiler vermesi; ardılı yazarları etkilemesi ve esin vermesi bakımından önem arz eden "Tarihin Babası"

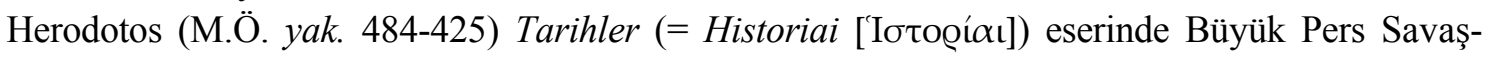
ları'nı anlatmakla Hellenlerin şan ve zafer; Thukydides ise, Peloponnesos Savaş anlatısı ve incelemesiyle Hellenlerin yıkım dönemlerinin tarihçileri olmuşlardır. Pers ve Peloponnesos savaşları yakın bir tarihte cereyan etmişti. Halikarnassos'lu Heredotos eserinin kurgusunu esas itibariyle Pers Savaşları üzerine odaklamıştır. Etnografik ve coğrafik unsurların yanı sıra kültür ve tarih bakımından özgül bir incelemedir. Hellenlerin ve Perslerin yanı sıra Lydia'lıların, Medlerin, Mısırlıarın, Arapların, Hintlerin, İskit ve Trakya v.d. halklarının örf-adetleri, sosyopolitik yapısı ve devlet rejimleri gibi çeşitli konularla metnini zenginleştirmesini bilmiştir. Topladığ yığınla coğrafik ve etnografik bilgiyi daha farklı bir odak noktasına sahip olan Pers Savaşları anlatısıyla birleştirmiş̧tir (Breisach, 2009, 39). Perslerin hayranlık duyulası adetlerinden, demokrasilerde kitlelerin oynaklığından, Hellen kent devletlerindeki patırtılı ithilaflara karşıllk Pers İmparatorluğu'ndaki dingin birlik ve beraberlikten özlemle bahsetmiştir. Persler konusunda sergilediği bu yaklaşım dikkate değer bir kozmopolitanlığa işaret eder. Hellen-Pers Savaşları'nın kökeni ve nedenlerinin analizini yaparken kısmen yansız bir tutum sergileyip, M.Ö. 499 yılındaki Sardeis kuşatması gibi ilk kıvılcımı körükleyenlerin Hellenler olduğuna vurgu yapar (V. 99-103). M.S. I.-II. yüzyıl arasında yaşamış dönemin entelektüellerinden Plutarkhos gibi bazı antik yazarlar, Herodotos'un bu bağlamda kısmen de olsa olumlu çizdiği 
Pers portresine şiddetle karşı çıkmışlardır. Plutarkhos Ethika eserinin Herodotos'un Kötülü̆̈̈u

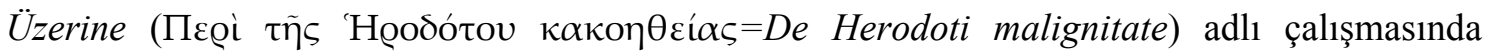
Herodotos'u kasten güvenilmez yabancı hikayeleri kabul ettirerek okuyucuyu aldatmakla tenkit eder. Yalancılıkla ve barbar severlikle (= philobarbaros [ $\phi \iota \lambda о \beta \alpha ́ \varrho \beta \alpha \varrho о \varsigma])$ itham eder. Böylece Hellenlerin ve kent devletlerinin saygınlığına gölge düşürdüğünü belirtir (Plut. mor. XI. $874 b$ -

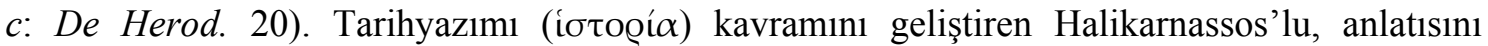
Perslerin Hellenler karşısında ağır yenilgiye uğradıkları M.Ö. 490-479 yılları arasındaki Salamis, Plataia, Mykale savaşlarıyla sona erdirir. Amacı Perslere karşı Hellenlerin kazandıkları zaferleri yüceltmekti. Bu bakımdan geniş kültür tarihi, Hellen kent devletlerinin, özellikle Atina'nın kurtuluşuyla sona erer (Kuhrt, 2007a II, 354; Breisach, 2009, 30).

Herodotos da seleflerinin metodoloji sistemini, yani önceli yazarların adlarına ve eserlerine atıfta bulunmama geleneğini sürdürmüş̧ür. Dolayısıyla tarihyazımında yararlandığı ve esin veren yazarları gerçek anlamda belirlemek meşakkatli bir iştir. Eserinde Homeros'un yanında Aiskhylos ve Atina'lı Phrynikhos gibi tragedya yazarların da olduğu yaklaşı on beş ozandan bahseder. Bazen eserinde tarihsel kaynak olarak onları referans verir. Nesir yazarlarından Miletos'lu Hekataios'u okuduğu ve yararlandığı kabul edilmektedir (II. 143-144; V. 36; 124-126). Olasilıkla Miletos'lu Dionysios'un Persika; Karyanda'lı Skylaks'1n Indika; Lydia'lı Ksanthos'un Lydiaka; Lesbos'lu Hellanikos'un Persika ve diğer eserleri; Lampsakos'lu Kharon'un çeşitli kitaplarından faydalanmış olması ihtimal dahilindedir (Marincola, 1997, 225-26; Scott, 2005, 12 vd.; Asher, Lloyd, \& Corcella, 2007, 18 vd.; Llewellyn, \& Robson, 2010, 49).

Herodotos eserini esas itibariyle birincil elden bilgiler (ő $\psi \varsigma$ ) ve sözel testimonya ( $\dot{\alpha} \kappa o \eta ́)$ olmak üzere iki ana tema üzerinde kurgulamıştır. Birincil bilgileri gözleriyle doğruluğunu sağlayan seyahatleri ve savaşa katılanların tanıklığı ve deneyimleriydi. Yazar Mısır, Fenike, Babil, Pontos kıyıları Byzantion'dan Olbia, Trakya kıyıları ve komşu adaları ziyaret etmiştir. Ionia, Karia, Lydia, Lykia ve Ege Adaları'nı (Samos, Lesbos); Hellas'ta Delphoi, Sparta ve Boiotia anakarasını da iyi bilmekteydi (Asher, Lloyd, \& Corcella, 2007, 6; ayrica bk. Scott, 2005, 6-8. M.Ö. 448-446 yılları arasında Mısır, Fenike ve Mezopotamya'ya; M.Ö. 445/444 y1lında Atina'ya ve sonra da Thurii'ye gitmiştir ayrıca bk. Asher, Lloyd, \& Corcella, 2007, 5). Kitabında kendisine hiç yer vermeyen Herodotos, seyahatlerini doğrudan ve açıkça belirtir: Nil boyunca

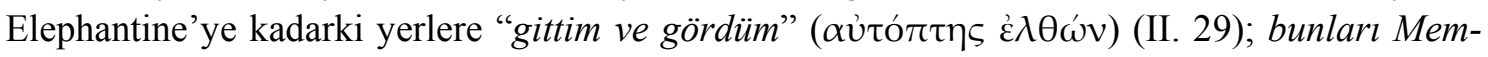
phis'te ögrendim; ayn zamanda Thebai ve Heliopolis'i de ziyaret ettim (II. 3); Thebai'da rahipler beni büyük bir holün içine aldılar (II. 143); şahsen Moiris Gölü'deki labirentin yüksek odalarını gördük (II. 148); Pelusium ve Papremis savaşında ölenlerin kemiklerini gördüm (III. 12); Arabistan'da Buto'nun karşısında bir saraya gittim (II. 75); Tyre'ye yelken açtım (II. 44); Babil tapınă̆ında Kserkses'in getirttiği heykeli görmedim (I. 183); Thasos'a gittim (II. 44); Thasos'ta madenleri gördüm (VI. 47); Eksampaios'ta bir krater gördüm (IV. 81); Thebe'de Kadmos harflerini gördüm (V. 59).

Herodotos tarihyazımını doğu dokümantasyonlarıyla örüntülemeye çalışsa da, dilbilim engeline takılmış olmalıdır. Olasılıkla çift dili yazıtlar, birinin tercümanı ve rehberliğiyle aşılmaya çalışılmıştır. Kambyses'in kardeşini öldürmesi, akabinde yaşanan Mag isyanı ve kralın ölümü (III. 64-66; DB col. I. 11: Kent, 1953, 116-120 col. I. 11. 1. 35-43); Dareios'un tahta geçiş anlatıs1 (III. 68-70; DB col. I. 13: Kent, 1953, 120 col. I. 13. 1. 48-61) ve Smerdis'e karşı birleşen yedi suikastçının adları (III. 70; DBcol IV. 68: Kent, 1953, 120 col IV. 68. 4. 80-86) BehistanBisutun yazıtıyla kısmen büyük bir uyumluluk sergilemektedir. Tahminen yazar bu kaya yazıtını yerinde görmüş ve tercüman çevirirken kendisi de kaydetmiştir ya da metinlerin içeriğini iyi bilen bir öncelinin anlatılarından esinlenerek kaleme almıştır. Herodotos'un phoros, nomos, Pers İmparatorluğu'ndaki asker kıtası, "Kral Yolu" arasındaki mesafe ve istasyonlar doğu kitabelerinden alıntılanmış olmalıdır. İddia edilenin aksine bu dizelgeleri oluştururken ne 
Homeros'un (Il. II. 490-875) gemi ve komutanlar kataloğunu ne de Aiskhylos'un (Pers. 10-60) skeçindeki Pers generaller listesini model almış olsa gerektir (Armayor, 1978, 7 vd.; Asher, Lloyd, \& Corcella, 2007, 480 vdd.). Pers küneiform tabletleri Herodotos'un Pers onomastik bilgisinin güvenilir olabileceği izlenimini sunmaktadır. Elbette tarihyazıcısı orijinal metinlere, Elamca, Akkadça, Aramice ile imparatorlukta sirkülasyonu olan resmi dokümantasyonların Pers kralı buyrultularını imparatorluktaki bölgelere her ulusun kendi alfabesi ve diliyle yazıldığ mektuplar vasıtasıyla iletirdi (Ester 1: 22)- diğer tercümanlarına başvurmamıştır. Olasılıkla çift dil bilen bir kılavuza adları dikte ettirmiş ve listelemiş olmalıdır (Asher, Lloyd, \& Corcella, 2007, 18). Herodotos doğu yazıtlarının yanı sıra kendisinin görüp nüshasını aldığ1 Hellence epigrafik yazıtlara da eserinde bolca yer vermiştir (Hdt. IV. 87; 88; VI. 14; 117; VII. 228; ayrica bk. Scott, 2005, 15; Asher, Lloyd, \& Corcella, 2007, 18).

Herodotos'un historiografyasında sıklıkla sözel tradisyonun izlerine rastlanmaktadır. Eserinde şark kökenli saray hikayelerine, Kyros'un doğuşu ve yetişmesine ilişkin doğu söylencelerine (I. 95; 108-130), Kambyses' in hükümdarlığının son yıllarında cereyan eden olaylara (III. 1-67), yedi Pers suikastçıya (III. 68-79), Dareios'un tahta geçişine (III. 80-87), Zopyros'un maceralarına (III. 153-157) ve Kserkses ile Masistes'in eşine ait hikayelere bolca yer vermiştir (IX. 107-108; 110-113). Anekdotların çoğu Pers krallarına ahlaki yergilerle doludur. Sayısız Pers epizotları III. kitabında (61-88), bilhassa Kambyses üzerinde yoğunlaşmaktadır. Kambyses portresini çizerken düşmanca bir tutum sergiler. Erkek kardeşiyle evlendiği kız kardeşini öldürecek kadar kibirli (hybris) ve ağır bir paranoyaya kapılmış gaddar bir zorba şeklinde tasvir eder. Kutsal Apis'i öldüren, Mısır'ın toplumsal-dinsel yaşamına zerre kadar sayg1 ve hürmet beslemeyen bir karakterdir. Ancak Vatikan'da yer alan, önceleri Mısır hükümdarının -Amasis (M.Ö. 570-526); III. Psammetikhos (M.Ö. 526-525)- ardından Pers kralının hizmetinde bulunan yüksek rütbeli memur Udjahorresne(t)'in otobiyografi niteliğindeki heykel kaidesine kazılan hiyeroglif yazıtta, Kambyses, anlatılanların aksine dindar; tanrısal vecibelerini bilen; egemenliğini olumlu ölçülerde kabulünü sağlayan ve de devraldığı Mısır hükümdarlık misyonunun gerekliliklerini yerine getiren bir kral betimlemesiyle sunulur (Posener, 1936, 1-26 n 1; Kuhrt, 2007a II, 375 vdd.; 2007b, 117-122).

c) Bütün yabancı ülkelerin Büyük Önderi, Kambyses Misır'a geldi, her bir yabancı ülkenin yabancı insanları kendisine eşlik ederken. Baştan sona bu ülkenin haşmetli efendiliğini kazandl. Bizzat kendileri burada yerleştiler /tesis ettiler, O Mısır'in Büyük Hükümdarı ve bütün yabancı ülkelerin büyük önderi idi.

Haşmetli efendi beni başhekimlik makamına atadi. Beni yanında bir "dost" ve "sarayın idarecisi" olarak ikamet ettirdi. Yukarl ve Aşağı Misır Kralı'nın adına onun Mesutire (Re'nin oğlu/dölü) unvaniyla müteşekkil oldum.

d) Haşmetli efendinin, henüz hiçbir soy olmamışken doğumu başlatan ve Re'yi doğuran ana Büyük Neith'in meskeni Sais'in azametini; her yönden cennet Neith

Tapınă̆ı'nın görkemli yapısını; buradaki bütün tanrl, tanrıça ve Neith'in şapelinin ihtişamlı doğasını; Gökyüzünün Efendisi, Hükümdarm oturduğu sarayın anitsal yapisini; Resenet ve Mehenet tapinaklarinin; Re'nin Evi ve tanrilarin gizemi Atum'un Evi'nin

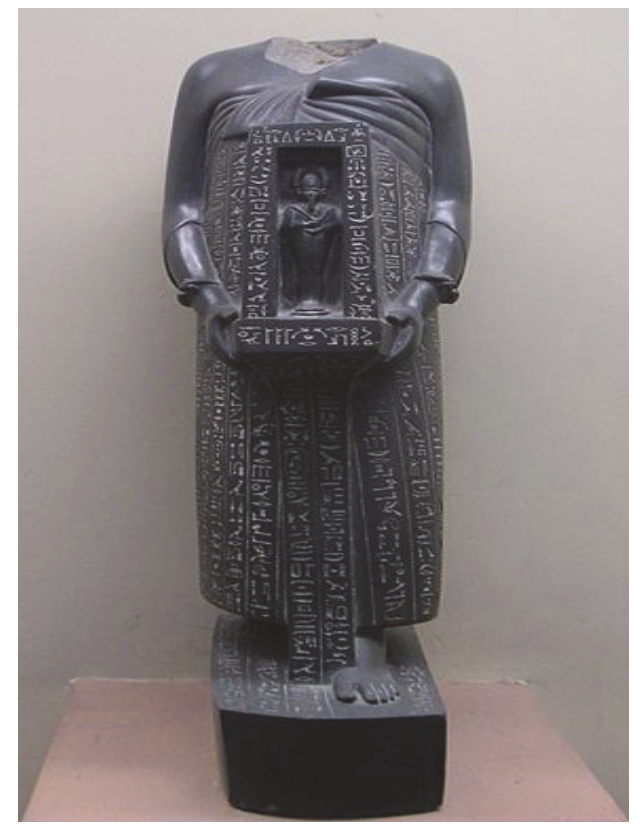

Şimdi Vatikan'da yer alan $0,70 \mathrm{~m}$. yüksekliğinde Udjahorresne(t)'in naophorous heykeli. İmparator Hadrianus'un Tivoli' deki villasında Mısır koleksiyonuna ait bir parça olduğu varsayılmaktadır. 
görkemli doğasın fark etmesine neden oldum.

e) Yukarı ve Aşağı Misır kralı haşmetli efendi Kambyses'ten Neith Tapınağı'na yerleşen bütün yabancılar yüzünden, Neith Tapınă̆ı'nın eskiden olmuş olduğu gibi, bütün görkemine kavuşmasl için onların oradan sürülmeleri gerektiğini rica ettim. $O$ vakit bizzat kendileri (bütün eşyaları) bu tapınă̆ın duvarının dışına çıkardılar. Haşmetli efendi Neith Tapınağı'nın arındırılmasını, bütün insanlarının [. . .] ve tapınă̆ın saat başı rahiplerinin restore etmelerini/ yerlerine dönmelerini emretti. Haşmetli efendi eskiden olduğu gibi sunuları tanırının anası ulu Neith'e ve Sais'teki yüce tanrlara verilmesini buyurdu. Haşmetli efendi, eskiden olduğu gibi, tanrlçanin bütün festivalinin ve ziyafetinin düzenlenmesini emretti. Haşmetli efendinin Sais'in önemini fark etmesini sağladı̆̆ım için efendi bunu yaptı. Sais, orada her zaman tahtlart üzerinde kalan bütün tanrlların kentiydi...

Mısır'da ele geçen iki hiyeroglif mezar yazıtı da Kambyses'in Mısır Krallı̆̆ı'nın kutsal buyrukları doğrultusunda hareket ettiğine işaret eder. Herodotos'un (III. 27-29) kutsal Apis öküzünü katlettiği ve rahibin ondan gizli gömdüğü anlatısının aksine, Kambyses M.Ö. 524 yılında ölen Apis'i gösterişli bir törenle ve görkemli sunularla defneder (Posener, 1936, $\mathrm{n}^{\circ} 3$; Kuhrt, 2007b, 122 vd. n ${ }^{\circ}$ 12). I. Dareios'un hükümdarlığının dördüncü yılından (= M.Ö. 518) kalma diğer Apis mezar yazıtında ise, Kambyses'in atadığı yeni öküzün ölümü kayda geçirilir (Posener, 1936, $\mathrm{n}^{\circ}$ 4; Kuhrt, 2007b, $124 \mathrm{n}^{\circ}$ 13). Bunun yanı sira Herodotos, Kserkses portresini sunarken Hellespontos'u üç yüz sopa çekip cezalandırması (VII. 35); Pythios'un oğlunun yazg1s1 (VII. 38-39); Leonidas'ın cesedine saygısızlığı (VII. 238) ve Delphoi Apollon Tapınağı'nın yağmalanması (VIII. 35-38) gibi bazen kralın uzlaşmaz, dizginlenemeyen ve sınır tanımayan despot davranışlar sergilediğinin altını çizer. Gerçi Kserkses'in tapınak tahrip ettiği genellikle Daiva Yazıtı şeklinde bilinen Kserkses Persepolis $(K P h)$ yazıtıyla da kanıtlanmaktadır: " $B u$ ülkeler/halklar arasında evvelce sahte tanrlara (daivā) tapınılan (bir yer) vardl. Sonradan Ahura Mazda'nın inayetiyle, iblislerin tapınağını yerle bir ettim ve şunu buyurdum: İblislere tapınılmasın. Önceden putlara tapınılan yerde, orada, ben, Ahura Mazda'ya doğru zamanda ve doğru bir şekilde taptyorum (KPh: Kent, 1953, 150-152 col. 4b 35-46; Wiesehöfer, 2003, 81 vd.). Gene de onu her şeyden tek sorumlu, kibir içinde sınır tanımayan biri olarak nitelemez. Kserkses olayların akışını tek başına belirlemez: Hellas'a sefer açmaya zorlayan fitneci sürgünler, hilekar falcılar, seferden vazgeçmişken uğursuz sonuçlar getiren tanrısal esinler; krallığının sınırlarını genişletmesi gerektiği vazife anlayışı, Ionia İsyanı'nı destekleyen Atinalılardan öç alma arzusu gibi etmenlerin tesiri altındadır (VII. 7-19). Herodotos'un Kserkses'i tarihsel olarak güvenilir karakter incelemesinden çok, önceden belirlenmiş yazgıyla insani biçimlendirme olanakları arasındaki bağıntıya ilişkin olarak tarihçi görüşlerini içermektedir (Wiesehöfer, 2003, 82; Breisach, 2009, 32 vd.).

Persika adlı eserler üzerine yapılan çalışmalardan en iyisi şeklinde nitelendirebileceğimiz, sonraki yazarlara öncülük eden ve esin veren, Pers sarayında uzun bir müddet Artakserkses II Mnemon'a (M.Ö. yak. 404-398/397) ve ailesine hekimlik yapan Knidos'lu Ktesias'ın (M.Ö. yak. 441-393/392) Persika yapitidır (FGrHist III C 1688 F 5 (5-6)=Diod. II. 32. 4-6; FGrHist III C 1687 T 2=Strab. XIV. 2. 15 c. 656; FGrHist III C 1688 T 8=Plut. Artaks. I. 2; Phot. Bib.

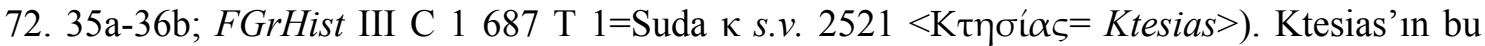
çalışması dışında Indika, Asya'daki Phoros/Haraç'lar Üzerine, Periodos/Periploi/Perigesis adlı üç kitabı daha bilinmektedir (FGrHist III C 1688 F 46-52 'Indika'; F 53-54 'Asya'daki Phoros/Haraç'lar Üzerine'; F 55-58 'Periodos/Periploi/ Perigesis'; ayrıca bk. Stronk 2010, 12 15). Persika eseri Sicilyalı Diodoros; Şamlı Nikolaos; Plutarkhos ve Photios'un genişçe yer verdikleri özetler ve alıntılar sayesinde fragmanlar şeklinde günümüze ulaşmıştır. Persika adlı eseri yirmi üç kitaptan oluşmaktadır. İlk dört cildinde Assur ve Babil (FGrHist III C 1688 F 1 (1-28)=Euseb. Chron. 28. 28-29; Diod. II. 1. 4-28; II A 90 F 3-4 'Nikolaos'=Const. Porph. de 
Virt. I. 329. 16; de Insid. p. 4. 23), dört-altınc1 cildinde ise Med (FGrHist III C 1688 F 58=Diod. II. 32. 4-34. 6; II A 90 F 4-5 'Nikolaos'=Const. Porph. de Virt. 330. 5; 335. 20) tarihi konu edindiği varsayılmaktadır (detaylı bilgi için bk. Llewellyn, \& Robson, 2010, 113-148). Yedi-on birinci ciltler II. Kyros'un hükümdarlığını; Kyros'un tahta geçişi ve Med krallığını devrilmesini ele almaktadır (FGrHist III C 1688 F 8d; 9=II A 90 F 66 'Nikolaos'=Const. Porph. de Insid. p. 23. 23; Phot. Bib. 72. 36a9-37b25). On iki-on üçüncü ciltler M.Ö. 530-465 yılarında vuku bulan olayları: II. Kambyses'in tahta geçişi; Mısır seferi; kardeşini öldürtmesi; Mag ayaklanması ve Kambyses'in ölmesi; Magların krallığ1; Dareios ve yedilerin Magları tahtan indirmeleri; Dareios'un başa geçişi; İskit Seferi; Datis'in Hellas Seferi; Kserkses'in hükümdarlı̆̆ı; Babil isyanı; Hellen-Pers savaşları çerçevesinde Thermopylai ve Plataia savaşları; Mardonios'un Delphoi'u yağmalaması; Atina'nın zapt edilmesi ve Salamis Deniz Savaşı; Kserkses'in Persis'e geri dönüşü; Kserkses'in bir komploya kurban gitmesini ihtiva etmektedir (FGrHist III C 1688 F 13 (9-33)=Phot. Bib. 72. 37a26-40a5). On alt1-on yedinci ciltlerdeki incelemenin odaklandığı alan I. Artakserkses'in (M.Ö. 465-424) hükümdarlığı esnasında cereyan eden olaylardır: Karşı komplo sonucunda I. Artakserkses'in tahta geçişi; akabinde yaşanan Baktria, Inaros ve Misır isyanı; Suriye'de Megabazos ayaklanması; kralın aslan avı ve Megabazos'un sürgünü; Kos'lu Apollonides ve Amytis'in ölümü; Zopyros'un Atina'ya sığınmas1; Amestris ve Artakserkses'in ölümü (FGrHist III C 1688 F 14 (34-46)=Phot. Bib. 72. 40a5-41b37). On sekizinci cilt II. Kserkses (M.Ö. 424); Sekyndianos (M.Ö. 424) ve Dareios II Okhos (M.Ö. 424-404) döneminde I. Artakserkses’ten II. Dareios'a kadarki süreçte yaşanan kraliyet ailesi ve veliaht krizini kapsamaktadır: Artakserkses'in bir komploya kurban gitmesi; Sekyndianos'un kısa süreli saltanat1, II. Dareios'un tahta geçişi; Aristes ve Artyphios, Pisuyhenes'in ayaklanması; hadım Artokserkses'in krala suikast1; Teritukhmes'in ayaklanmas1 (FGrHist III C 1688 F 15 (47-56)=Phot. Bib. 72. 41b38-43b2). On dokuz-yirminci ciltler II. Artakserkses'in hükümdarlığı; Genç Kyros'un abisine karşı yürüttüğü savaş ve hazırlıkları; Kunaksa Savaşı ve Kyros'un ölümünü içermektedir (FGrHist III C 1688 F 16-26 (57-67)=Phot. Bib. 72. 43b3-44a19; Plut. Artaks. II. 3-III. 6; VIII. 2; IX. 1-4; XI. 1-6; XII. 1-4; XIII. 1-4). Yirmi bir-yirmi üçüncü ciltler M.Ö. 404-359/358 yılında II. Artakserkses'in hükümdarlığ 1 sırasında cereyan eden olaylarla devam eder: Tissaphernes'in Hellen komutanlarını hileyle ele geçirmesi; Klearkhos ve diğer komutanların öldürülmesi; Klearkhos'un mezarı; kraliçe Stateira'nın zehirlenmesi; Samos'lu Euagoras ve Artakserkses arasında müzakere; Konon ile Artakserkses'in görüşmesi; uzaklıklar ve krallar listesiyle de son bulur (FGrHist III C $1688 \mathrm{~F}$ 27-33 (68-76)=Phot. Bib. 72. 44a20-45a1-4; Plut. Artaks. VI. 9; XVIII. 1-5; XIX. 1-6; XXI. 1-4).

Pers Tarihi üzerine yapılan çalışmalar arasında Knidos'lu Ktesias'ın eseri önemli bir yere sahiptir. Ktesias'ın Persika'sı diğer tarihyazıcılarına nazaran daha az Hellen merkezli bir yaklaşım, önyargılardan arınmış, yansız ve güvenilir bir çalışma izlenimi vermektedir. On yedi yıla aşkın kaldığı Artakserkses II Mnemon'un sarayında Persleri yakından tanıma; aynı zamanda olasılıkla Eski Persçe ve resmi bürokrasi yazışmalarında kullanılan Aramice dillerini öğrenme firsatı bulmuştur (FGrHist III C 1688 F 23 (5-6)=Plut. Aratks. XIII. 4-7; ayrıca bk. Llewellyn, \& Robson, 2010, 56). Dolayısıyla Ktesias'ın eseri diğer kaynaklardan edinemeyeceğimiz birincil elden bilgilerle doludur. Olasılıkla kaleme aldığ1 eserinin II. Dareios (M.Ö. 424-404) ile II. Artakserkses'in hükümdarlığı sırasında yaşanan olaylara canlı tanıklık etmesi ve devrinin akışına yön veren bazı tarihi olgularda aktif şekilde yeralması anlatısını tarihsel gerçekler çevresinde örüntülediğine/kurguladığına işaret etmektedir (FGrHist III C 1688 F 30 (72-75)=Plut. Artaks. XVIII. 1-4; XXI. 2-4; Phot. Bib. 72. 44b 20-42 'Ktesias'; ayrica bk. Llewellyn, \& Robson 2010, 13 vd.). Ktesias kitabının ilgili kısımlarında Perslerin önde gelenlerin anlatımları, söylenceleri ve arşivleriyle Hellen yazarlarının kaleme aldıklarının kıyaslamalı analizini yapmıştır. Sicilyalı Diodoros (FGrHist III C 1688 F 5 (5-6)=II. 32. 4-6) Knidos'lu Ktesias'in Persika'sinda yer alan Perslerin eski zamanlardan itibaren edimlerinin kayıtlarının tutulduğu kral belgelerinden (= 


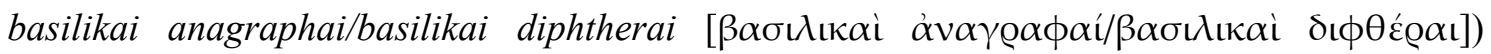
yararlanır. Her bir krala ilişkin dikkatli bir araştırma yapar. Bunları Hellenlerin yayınladığı tarih kitaplarıly kıyaslar. Photios (FGrHist III C 1688 T 8=Bib. 72. 35a-36b 'Ktesias'; ayrıca bk. Plut. Artaks. VI. 6)'de Ktesias'ın kitabında değindiği olayların birçoğuna tanıklık ettiğini; mümkün olmadığı zaman bizzat Perslerin bilgilerine başvurduğunu iddia eder. Eserinde Herodotos'un anlatısını çürütecek tam aksine olgulara değinerek tarihçiyi sık sık yalancılıkla

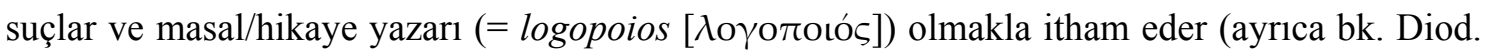
II. 15. 2). Herodotos'un anlatısından birçoğuna karşı çıkar: Herodotos'un (I. 108-130) Kyros'un çocukluğu, Astyages'le akrabalık bağı ve Med Krallığı'nı ele geçirişine ilişkin anekdotlarının doğruluğunu kabul etmez ve bu gelişmeleri değişik bir versiyonla kaleme alır (FGrHist III C 1 688 T 8=Bib. 72. 35b35-36b6 'Ktesias'); Herodotos'un Babil'in ele geçirilişinde baş aktör olan Zopyros hakkında "katır doğmadıkça Babil alınamaz" kehaneti çerçevesinde örüntülediği anlatısını Ktesias, Kserkses'in kızı Amytis'le evlenen Megabyzos'a atfeder (FGrHist III C 1 688 F $13(26)=B i b .72 .37 \mathrm{a} 26-40 \mathrm{a} 5$ 'Ktesias'). Pers geleneklerinde birinin adetleri çiğneyip ölüyü yakmasının mümkün olmadığını belirtir. Bu bağlamda Hellanikos ve Herodotos'u (III. 16: olasılıkla 'Kambyses'in Amasis'in naaşını yaktırması' anekdotu) tekziple itham eder (FGrHist III C 1688 F 16 (62)=Bib. 72. 43b3-44a19 'Ktesias'). Ayn1 zamanda bazı konularda Gryllos'un oğlu Ksenophon'la da fikir uyuşmazlığına düşer (FGrHist III C 1688 T 8=Bib. 72. 35b35-36b6 'Ktesias'). Plutarkhos (Artaks. XIII. 4) Ktesias'in Klearkhos ve Lakedaimon'lulara ilişkin değinisinde yansız bir tutum sergileyemediğini, Lakedaimon'lulardan her zaman güzel ve övgü dolu sözlerle bahsettiğini belirtir. Biyografi yazarının (Artaks. I. 2; V. 6) Ktesias'1 sürekli tenkit ettiği diğer bir nokta ise, eserinde abartılı söylencelere gereğinden fazla yer vermesidir. Lakin Ktesias'1 değerlendirirken bugün yitik olan özgün çalışmalarından çok ondan alıntı yapan antik yazarların yaklaşımlarını yansıttı̆̆ 1 gerçeği göz ardı edilmemelidir.

Kolophon'lu Dinon, M.Ö. yak. 360/330, (FGrHist III C 1690 T 2=Plin. nat. X. 136) İskender tarihçisi Kleitarkhos'un babasıdır (tarihyazıcısı Dinon şeklinde adlandırıldığı gibi bazen Deinon ya da Dion olarak da hitap edilir bk. Ath. Deip. II. 67b; Suda $\delta$ s.v. $1239<\Delta i ́ \omega v=D i-$ on>). M.Ö. 330 yılında Semiramis'in hükümdarlığından III. Artakserkses'in M.Ö. 343/342 Misır'1 yeniden fethine kadarki süreci kapsayan bir Assur ve Pers tarihi yazmıştır (FGrHist III C 1690 F 7-8; 21; tarihlemesi için bk. Stevenson, 1997, 10; Binder, 2008, 60 dn. 268; Llewellyn, \& Robson, 2010, 53). Persika kitabından günümüze otuz fragman korunagelmiştir (FGrHist III C 1690 T 1-5 F 1-30). Historiograf önemli ölçüde Ktesias'ın eserinde yararlanmıştır; ancak körü körüne alıntılamamıştır (Lenfant, 2007, 206; Llewellyn, \& Robson, 2010, 53). Plutarkhos Artakserkses biyografisinde Ktesias'la birlikte Dinon'u mukayese eder (I. 2; VI. 6; IX. 4; XIII. 3; XIX. 2-4). Tarihyazımlarının güvenilirliği bakımından önceliği Knidos'lu Ktesias'a verir (I. 2; V. 6). Dinon uzun süre Küçük Asya'da ikamet etmiştir. Bu esnada edindiği bir mevki sayesinde Pers İmparatorluğu'nun yapısı hakkında araştırma yapacak ölçüde deneyime sahip olduğu düşünülmektedir. Kitabında tahminen Sardeis satrapı Tiribazos'un hane halkından birinin aracılığıyla Pers sarayındaki birinci elden kaynakları edinip yararlandığı savlanmaktadır (FGrHist III C 1690 F 18; ayrıca bk. Stevenson, 1997, 13). Dinon'un Persika'sı Ktesias'ın eserinin gölgesinde kalmış ve onun kadar geniş okuyucu kitlesine ulaşmamıştır. Ktesias stilinde küçük tarih yazıcıllğı gerekçesiyle yergili ve iğneli sözlere maruz kalmasına rağmen, kendisinden sonraki jenerasyon antik yazarların nezdinde takdir toplamış ve başarılı bulunmuş gibi görünür (FGrHist III C 1690 F 18). Dinon'un yapıtı tarihi kaynaklar külliyatı şeklinde değerlendirilmiştir (Drews, 1973, 117; Lenfant, 2007, 206; Llewellyn, \& Robson, 2010, 54). Fragmanlarin büyük çoğunluğu M.S. II. yüzyılda yaşamış Athenaios'un Sophistlerin Ziyafeti (= Deipnosophistai

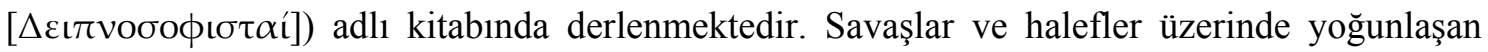
konvansiyonel/geleneksel Pers tarihyazımından ziyade saray toplum yapısı ve elit sınıfı incelediği; 
aynı zamanda Pers teolojisine ilgi gösterdiği anlaşılmaktadır.

M.Ö. IV. yüzyıl yazarlarından Kyme'li Herakleides'e ilişkin yok denecek kadar az bilgi vardır. Aynı sınırlı veriler yazarın beş kitaplık Persika eseri içinde söz konusudur (FGrHist III C 1 689 T 1=Diog. Laert. V. 93). Günümüze yedi fragman korunagelmiş̧ir (FGrHist III C 1689 F 1-7). Bu parçalardan dördü Athenaios'un doğrudan yaptı̆̆ alıntılar sayesinde ulaşmıştır. Kyme'li Herakleides'in Assur ya da Med tarihine ilgi duyduğuna dair herhangi bir veri yoktur. Olasılıkla eserini yalnızca Pers tarihi üzerinde odaklamıştır. Kalan fragmanlardan ikisi saraydaki bazı melodramatik olaylar -Themistokles'in Kserkses'le buluşması ve II. Artakserkses'in öz kızıyla yaptığı zina evliliği v.d.- konu edinmiştir (FGrHist III C 1689 F 5-7=Ath. Deip. II. 31. 48c-49a; Plut. Them. XXVII. 1; Artaks. XXIII. 6). Athenaios'un alıntıladığı uzun pasajda Herakleides'in eserinin temel örgüsünü saray yaşamının detayları; kraliyet şölenleri; harem; muhafızlar ve saray güvenliği üzerine kurduğu anlaşılmaktadır (FGrHist III C 1689 F 1-4=Ath. Deip. XII. 8. $514 b$-c; IV. 26. 145a-146a; XII. 13. $517 b$-c). Dinon tarih anlatisinda II. Artakserkses'in saray propagandasını anımsattığı ve Tiribazos'un ev halkıyla yakın ilişkisini yansıttığı izlenimini sunarken, Herakleides saray etiğinin detaylarına yoğunlaşmıştır. Her iki yazar da Ktesias'ın eserini temel ve birinci kaynak olarak kullanmışlardır (Llewellyn, \& Robson, 2010, 55).

Nitekim, M.Ö. V-IV. yüzyıllarda Persika eserlerinde yaşanan ivme Perslerin Küçük Asya ve Hellas'taki egemenlik ve emperyalist edimleriyle koşutluk sergilemektedir. Farklı bir ulus, dil, gelenek ve kültürün boyunduruğu karşısında asimilasyon korkusu kentleri ulus kimliklerini hatırlamaya yöneltmiştir. Tarihyazıcılı̆̆ 1 kimi zaman bilinçli kimi zaman bilinçsiz olarak üstünlük iddialarını meşruiyet kazandıracak "ötekiler" yaratmaya katkıda bulunmuştur. Erken dönem historiografların ve ardıllarının eserlerinde barbar kavramındaki önyargılarıyla Pers İmparatorluğu'nu güçlü ve kökten farklı haline getirdikleri bir sistemin izlerini görmek mümkündür. Persika yapıtlarının temel motifinin Hellen-Pers savaşlarının yanı sıra Perslerin sosyo-politik, idari yapısı, teolojisi, gelenek-görenekleri, eğitim sistemini de kapsamasının arkasında bu anlayış olsa gerektir. Tahminen birbirleriyle ortaklaştıkları ve ayrıştıkları özelliklerin sınırları belirlenerek Perslerden üstün yanlarını vurgulamak amaçlanmıştır.

Küçük Asya historiograflarının Pers imgelemindeki betimin ve düşünsel yargının tam bir tasavvuru yapılamasa da Hellen yazarlarından pek de farkl1lık sergilememiş olsa gerektir. Diğer historiograflarla kıyaslayınca Herodotos ile Knidos'lu Ktesias'1 tarihyazımlarının özgül, nesnel ve yansız olduğu dile getirilmekle birlikte her iki yazarın taraflı yaklaşımdan tamamen arınamayıp kendi halklarını yücelttikleri gözlenebilmektedir. Persika ve Perslere dair tarih anlatılarının neredeyse bütününde Kserkses'in Hellas Seferi, mağlubiyeti ve olumsuz karakteri konu edilmiştir. Klasik Dönem ve daha sonraki yazarların yazınında Pers karakter özelliklerinin dejenerasyonu ve bunun sonucu ortaya çıkan Kserkses'in egemenliğinden itibaren başlayan Pers iktidarının çöküşüne vurgu yapılmıştır. Hellen tragedya yazarlarından Aiskhylos'un (Pers. 584590) Kserkses' in yenilgisinin ardından krallığın durumunu özetlediği pasajı bu kanı için güzel bir paradigmadır: "Uzun müddet Asya topraklarl boyunca ikamet eden insanlar Persler tarafindan artık hükmedilmiyorlar, ne haraç ödüyorlar bir efendinin zorlamalartyla, ne de secde ederek korkuyla karışık saygı duyuyorlar. Çünkü krallığın gücü tamamen yok olmuştu". Hellenlerin utkularının nedenine bireysel ve kolektif özgürlükten doğan bağımsızlık gücü; yoksul ama bozulmamış bir halkın kırılmamış enerjisi öne sürüldü: Demosthenes (Phil. (3) IX. 36-40) kendi sözleriyle bunu şöyle ifade eder, "Atinalılar Perslerin zenginliğini alt eden, Hellas'a özgürlük getiren, ne denizde ne de karada bozguna uğratılamayan bir şeydi”. Buna karşın yüksek mevki sahiplerinin bile huzuruna bir köle gibi çıktıkları despot Pers kral tiplemesi, lüksün-şatafatın sürekli kurbanları, özellikle de karakterlerindeki yumuşama (=

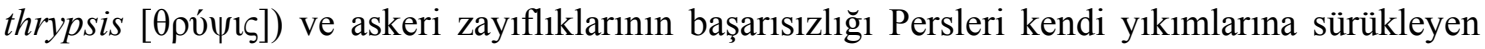


etmenler olarak algılandı. Aiskhylos Persai eserinde büyük kral tablosunu Kserkses'le özdeşleştirdiği sınırsız bir yetki, yasalarının üstünde bir güç, yaptıklarının hesabı sorulamayan despot ve tiran tiplemesiyle temellendirdi. Herodotos'un (IX. 122)'da kitabın1, kendilerini küçük ve dağlık ülkelerden çıkarıp egemen halka yaraşır yerlere iskan ettirsin diye sıkıştırılan Kyros'un Perslere verdiği söylemle bitirmesi oldukça manidardır: "Bunu yapabilirler, ancak artık hükmetmeye değil, egemenlik altında yaşamaya hazır olmalarl gerekir. Zira sert olmayan toprak yumuşak insanlar doğurur. Bir topraktan hem iyi hem de savaşçı yetişmez". Platon (Leg. III. 695b-e) ve Ksenophon (Kyr. VIII. 8. 2) çöküşün nedenini eski Pers gelenekleriyle yetiştirilmek yerine kadın ve hadımların eşliğinde sefahat, lüks ve ölçüsüzlükten ibaret olan saray eğitimine bağlar. Platon'un bu yapıtında öncelik ideal bir yönetim biçimine ulaşmaktır. Yurttaşların ahlaklı-erdemli yaşantı tarzını ön plana çıkardığı, devletin iyi yönetilmesi için gerekli kuramlar silsilesidir. Platon'a göre bunun gerçekleşmesi için temel faktör köklü reformdan oluşan bir eğitimin gerekliğidir. Dolayısıyla taht varislerinin yanlış eğitiminde Pers idari düzeninin çöküşünün ana nedenini görmesi şaşırtıcı değildir (Wiesehöfer, 2003, 132). Filozof Nomoi/Yasalar adlı çalışmasında acımasızca kritiğini yapıtığı Pers eğitimini Alkibiades (I. 121d$122 b$ ) adlı eserinde örnek alınacak kadar övmektedir. Zira yazarın diyalogunda amacı ünlü bir politikacı, hatip, kumandan olarak Alkibades'in rakipleri ve düşmanlarıyla -Spartalılar ile Perslerkıyaslanınca dönemin siyasetine damga vuracak kadar yeterli donanıma sahip olmadığını gösterip eksikliğini gidermek hedeflenmektedir. Knidos'lu Ktesias (FGrHist III C 1688 F 13 (9-33); 15 (47-56) imparatorluğun gerilemesi ve çöküşündeki asıl etmeni kral oğullarının eğitiminde değil, kadınların ve hadımların politik entrikalarında arar.

Isokrates (Paneg. 138-149) bir zamanlar Perslerle yapılan savaşın Hellen siyasi yaşamında bir birlik ve süreklilik duygusu yarattığını idrak etmişti. Dolayısıyla yeniden milli birlik tutkusunu körüklemek adına Perslerle girişilecek savaşı yararlı görüyordu. Büyük Kral'a karşı Panhellenizm birleşmesi adına yaptığı söylevlerinde saray duvarlarının altında Perslerin yumuşaması ve kölece zihniyetiyle gerekçelendirdiği askeri zayıflı̆̆a çekmektedir. Plutarkhos (Artaks. XX. 1-2) M.Ö. 401 yılındaki Kunaksa Savaşı'nda Kyros'un yenilgisinin akabinde Ksenophon öncülüğünde onbinlerin Büyük Kral'ın ordusunun elindeyken avuçları arasından ve Pers İmparatorluğu topraklarından çok az bir kayıpla kurtulmaları, Perslerin ve kralın yetkisinin öngörülerinin aksine bol altın, lüks ve kadınlar; geriye kalanın ise hava, boş gösteriden ibaret olduğunu Hellas kentlerinin algılamasını sağladı. Lakedaimon'lular önderliğinde Asya'da ikamet eden Hellenleri kölelikten kurtarma misyonunu yüklenip savaşa girişecek kadar Persleri hor gördüler. Ayrıca Plutarkhos (Artaks. XXIII. 3) krallığın gücünü yitirme sebepleri arasında lüks, şatafat ve politik komploların yanı sıra kraliyet adetlerinde baba ve kızın evliliğinden doğan ensest ilişkilerin yarattığ1 ahlaki çöküntülere dair anekdotlara da bolca yer verir. Hellenler nezdinde Persler sadece siyasi, ahlaki ve askeri zaaflık, çöküntü içinde değilerdi; aynı zamanda erdem ve bilimden de yoksundular. Salt felsefenin değil; aynı zamanda insan soyunun da Hellenlerle başladığına inanan Diogenes Laertios (I. 1-3; 4-5) filozofların öncülerinin Perslerden Maglar, Babiller ve Assurlar olduğu savını çürütme amacı gütmüştür. Bunu iddia edenleri, Hellenlerin başarılarını yazarın deyişiyle barbarlara mal ettiklerinin bilinçsizlik gafletliğiyle itham etmiştir.

Sonuç itibariyle fragmanlar halindeki Miletos'lu Dionysos'tan Ktesias'a kadarki Persika çalışmalar içerik, tema ve II. Kyros'un başa geçişi, imparatorluğun genişlemesiyle Kserkses'in mağlubiyeti ve krallık kudretinin hezimeti gibi olaylar dizgisini, Herodotos'un Historiai eserinin örüntüsüyle benzer bir şekilde ele almışlardır. Herodotos'un, Plataia utkusuyla noktaladığ 1 eseri Hellenleri yücelttiğinden hoş karşılansa da, çoğu zaman çizdiği pozitif Pers portresi bazı yazarların tahammülsüzlüğüne yol açmıştır. Plutarkhos De Herodoti malignitate eserinde tarihçiyi Persleri bazı noktalarda övdüğü için acımasızca tenkit ederken; Hellenlerin üstün kimliğini 
kanıtlamak istercesine kaleme aldığı Artakserkses çalışmasının bütününde, Persleri bir dizi olumsuz yanlarını ön plana çıkararak küçümser ve sürekli eleştirel bir bakış açısı taşır. Persler ve elit kesimleriyle yakın ilişkiler içerisine giren Ktesias ile Dinon'dan itibaren Persika yapıtlarının ilgi odağının dokusunda siyasal tarihi, teolojisi, kültürü ve idari yapılarını konu edip kapsayan değişik bir yaklaşım nüksetmiş ve eserler zamandizinsel olarak M.Ö. 479 yılıyla sınırlanmamıştır. Bazen Lakedaimon yanlılığından kendini alamasa da, Ktesias yalan yanlış bilgilerle betimlenen Persleri bizzat kendi tecrübelerinden edindiği gerçeklikleriyle tanıtmaya çalışmış ve Hellen yazarların her birini inceleyip eleştirmiştir. Kitabı Hellen zihniyetinde kalıplaşmış Pers imgesinin algı süzgecinden geçerek ele alındığından eserin günümüze ulaşmaması büyük bir kayıptır. Hellen ve Küçük Asya yazarlarının eserlerinin genelinde Persler ideolojik eğilimlerin egemen olduğu birtakım ayrımlaşmış ve onlarla özdeşleşmemiş usullerle araştırılır, tasavvur edilir ve öğretilir. Akhaimenid İmparatorluğu'nun devasa ordu ve varsıllığıyla Küçük Asya ile Hellas kentlerine saldığı tedirginliğin yersizliği, Pers savaşımlarını sürdürmek adına düşünülen kanının aksine aslında krallığın yetkisi, idarisi ve ordusunun zayıflığını gözler önüne sermeye; Platon, Isokrates gibi yazarların bireysel ideolojik savlarını desteklemeye hizmet sisteminin izleri görülür. Perslerden barbar diye söz etmek dili, coğrafyası, idari rejimi ve gelenekgörenekleriyle farklılık sergilediklerini nitelemek değildi yalnızca; çoğu zaman alt soydan bir halkı imleyen küçültücü ifade şeklinde de kullanılıyordu. Nitekim kültürler her dönem başka kültürleri oldukları gibi değil; kendi algıları doğrultusunda duyumsayıp alımlayarak onlara bütünsel dönüşümler dayatma eğilimi sergilemişlerdir.

\section{KAYNAKÇA}

Ael. Var. Claudius Aelianus, Varia Historia. Historical Miscellany. Trans. N. G. Wilson (1997). Cambridge, Mass.-London: Loeb.

Aiskh. Pers. Aiskhylos, Aeschylus: Persians and Other Plays. Trans. C. Collard (2008). New York: Oxford University Press 2008.

$\mathrm{AJPh}$, American Journal of Philology.

Armayor, O. K. (1978). Herodotus' Catalogues of the Persian Empire in the Light of the Monuments and the Greek Literary Tradition. TAPhA, 108, 1-9. Atlanta, Georgia.

Asher, A., Lloyd, A., \& Corcella, A. (2007). A Commentary on Herodotus Books I-IV. New York: Oxford University Press.

Ath. Deip. Athenaios, The Deipnosophistis. Trans. C. B. Gulickvol. I-VII (1927-19996). Cambridge, Mass.-London: Loeb.

Breisach, E. (2009). Tarihyazımı. Çev. H. Koçak. İstanbul: Yapı Kredi Kültür Sanatçılık.

Dem. Phil. Demosthenes, Orations I-XVII, XX: Olynthiacs; Philippics; Halonnesus; Minor Public Orations; Speech Against Leptines. Vol. I. Trans. J. H. Vince (20047). Cambridge, Mass.-London: Loeb.

Dion. Hal. Thuk. Dionysios Halikarnasseos, Dionysii Halicarnasei quae exstant, vol. 5. Ed. H. Usener, \& L. Radermacher (1899 repr. Stuttgart: 1965). Leipzig: Teubner.

Dio Khrys. Orat. Dio Chrysostomus, Discourses, vol. III. Trans. J. W. Cohoon, \& H. L. Crosby $\left(2006^{6}\right)$. Cambridge, Mass.-London: Loeb.

Diod. Diodorus of Sicily. Trans. R. M. Geer (1947). London, New York: Loeb.

Diog. Laert. Diogenes Laertios. Ünlü Filozofların Yaşamları ve Öğretileri. Çev. C. Şentuna (2003). İstanbul: Yapı Kredi Yayınları.

Drews, R. (1973). The Greek Accounts of Eastern History. Cambridge, MA: Harvard University Press.

Euseb. chron. Eusebi, Chronicorum (Liber Prior). Ed. A. Schoene (1875). Berlin.

FGrHist Die Fragmente der griechischen Historiker. F. Jacoby. 1-XV. Berlin-Leiden.

Fowler, R. L. (1996). Herodotus and his Contemporaries. JHS, 116, 62-87. London.

Hdt. Herodotus. Trans. A. D. Godley I-IV (1975). London, New York: Loeb. 
Hes. lex. Hesychius Alexandrinus, Hesychii Alexandrini lexicon, vol. I-II [A-O]. Ed. K. Latte (I. 1953; II. 1966: 3-492; 1-806). Copenhagen: Munksgaard.

Hom. Il. Homeros, İlyada. Çev. A. Erhat-A. Kadir $\left(1993^{7}\right)$. İstanbul: Can Yayınları.

Isok. Paneg. Isokrates, Panegyricus: Isocrates. Trans. G. Norlin I-II $\left(2000^{7}\right)$. Cambridge, Mass.-London. Jacoby, F. (1922). Ktesias, RE. XI col. 2032-2037. London.

JHS Journal of Hellenic Studies.

Kent, R. G. (1953). Old Persian. New Haven: American Oriental Society.

Ksen. Kyr. Xenophon, Cyropaedia, vol. V-VI: Books 1-4; 5-8. Trans. W. Miller (1914). London, New York: Loeb.

Kuhrt, A. (2007a). Eski Çağ’da Yakındoğu M.Ö. 3000-330. Çev. D. Şendil. İstanbul: Türkiye İş Bankası Kültür Yayınları.

Kuhrt, A. (2007b). The Persian Empire. A Corpus of Sources from the Achaemenid Period. II vols. London: Routledge.

Lenfant, D. (2007). Greek Historians of Persia. Ed. J. Marincola. A Companion to Greek and Roman Historiography, vol. 1, 201-209. Oxford: Wiley Blackwell.

Llewellyn, J., L., \& Robson, J. (2010). Ctesias History of Persia Tales of the Orient. London and New York: Routledge Classical Translations.

JSOT Journal for the Study of the Old Testament.

Marincola, J. (1997). Authority and Tradition in Ancient Historiography. Cambridge: Cambridge University Press.

Oxyrh. Pap. Oxyrhynchus Papyri XIII. Ed. with Trans. and Notes by B. P. Grenfell, \& A. S. Hunt (1919). London.

Paus. Pausanias, Pausanian Description of Greece. Trans. W. H. Jones I-V. (1918-1935). London, New York: Loeb.

Phot. Bib. Photios, Bibliotheka. Ed. R. Henry (1971), Paris: Duckworth.

Plat. Leg. Platon, Leges: Plato, Plato in Twelve Volumes, vol. 10 \& 11. Trans. R. G. Bury (1967-1968). Cambridge, Mass.-London: Loeb.

Plat. Alk. Platon, Alkibiades: Plato in Twelve Volumes, vol. 8. Trans. W. R. M. Lamb (1955). Cambridge, Mass.-London: Loeb.

Plin. nat. Plinius Caecilius Secundus, Pliny Natural History. Trans. H. R. Rackham, W. H. S. Jones, \& D. E. Eichholz. I-X (1938-1971). Cambridge, Mass.-London: Loeb.

Plut. Artaks. Plutarkhos, Artakserkses: Plutarch's Lives. Trans. B. Perrin I-XI. (1959). London, New York: Loeb.

Plut. Them. Plutarkhos, Themistokles: Plutarch's Lives. Trans. B. Perrin I-XI. (1959). London, New York: Loeb.

Plut. mor. Plutarkhos, Plutarch's Moralia. Trans. F. C. Babbitt, \& W. C. Helmbold I-XIV (1928-1967). London, New York: Loeb.

Posener, G. (1936). La Première domination perse en Égypte: recueil d'inscriptions hiéroglyphiques. Cairo: Institut Français d'Archéologie Orientale.

RE Paulys Real-Encyclopädie der classichen Altertums-wissenschaft.

Schol. Aristoph. Av. Scholia in Aristophanem: Aves. Ed. V. Coulon, \& M. van Daele (1928 repr. 1967). Aristophane, vol. 3. Paris: Les Belles Lettres.

Schol. Dion. Thrak. Scholia Commentaria in Dionysii Thracis Artem Grammaticam. Ars grammatica. Ed. G. Uhlig (1883 repr. Hildesheim: Olms, 1965: 5-100). Grammatici Graeci, vol. 1.1. Leipzig: Teubner.

Schol. Hdt. Scholia in Herodotum, Historiae. Ed. Ph.-E. Legrand (1: 1932; 2; 1930; 3: 1939; 4 (3rd edn.): 1960; 5: 1946; 6: 1948; 7: 1951; 8: 1953; 9: 1954 (repr. 1: 1970; 2: 1963; 3: 1967; 5: 1968; 6: 1963; 7: 1963; 8: 1964; 9: 1968). Herodote. Histoires, vol. 9. Paris: Les Belles Lettres.

Schol. Hom. Il. Scholia in Homerum, Ilias. Ed. T. W. Allen (1931: 1-356; 1-370). Homeri Ilias. vol. II- 
III. Oxford: Clarendon Press.

Schol. Lucan. Lucianus Scholia in Lucianum (scholia vetera et recentiora Arethae). Ed. H. Rabe (1906 (repr. Stuttgart: 1971): 1-285). Leipzig: Teubner.

Schol. Plat. Rep. Scholia in Platonem, Respublica (scholia vetera). Ed. W. C. Greene (1938: 1 1-405, 407-413), Scholia Platonica. Haverford, Pennsylvania: American Philological Association.

Scott, L. (2005). Historical Commentary on Herodotus Book 6. Leiden, Boston: Mnemosyne.

Strab. Strabon, The Geography of Strabo. Trans. H. L. Jones I-VIII (1917-1932). London, New York: Loeb.

Steph. Byz. Ethnika. Stephanos Byzantios, Stephani Byzantii Ethnica, volumen I: alpha-gamma. Trans. M. Billerbeck (2006). Berlin: Walter de Gruyter Berolini et Novi Eboraci MMVI.

Stevenson, R. B. (1997). Persica. Greek Writing about Persia in the Fourth Century BC. Edinburgh: Scottish Academic Press.

Stronk, J. P. (2010). Ctesias' Persian History: Introduction, Text and Translation. Wellem Verlag, Düsseldorf.

Suda Suda-Suidas, Suidae Lexicon. Ed. A. Adler I-IV (1928-1971). Leipzig: Teubner.

TAPhA Transactions and Proceedings of the American Philological Association.

Tert. An. P. Terentius Afer, Andria. The Comedies of Terence. Trans. H. T. Riley (1874). New York: Harper \& Brothers, Publishers.

Theophr. fr. Theophrastus Philosophus, Theophrasti Eresii opera, quae supersunt, omnia. Ed. F. Wimmer (1866 repr. Frankfurt am Main: Minerva, 1964:364-410, 417-462). Paris: Didot.

Thuk. Thukydides, Peloponnes Savaşı. Çev. T. Gökçöl (1976). İstanbul: Hürriyet Yayınları.

Toye, D. L. (1995). Dionysius of Halicarnassus on the First Greek Historians. AJPh, 116, 279-302. Baltimore.

Wiesehöfer, J. (2003). Antik Pers Tarihi. Çev. M. A. İnci. İstanbul: Telos. 